\title{
Secagem ao ar livre da madeira serrada de eucalipto
}

\author{
Linéia Roberta Zen ${ }^{a^{*}}$, Thiago Campos Monteiro ${ }^{a}$, Winicius Schaeffer ${ }^{\mathrm{a}}$, João Marcelo Kaminski ${ }^{\mathrm{a}}$, \\ Ricardo Jorge Klitzke \\ ${ }^{a}$ Universidade Federal do Paraná, Brasil \\ *Autor correspondente (lizenflorestal@gmail.com)
}

\section{N F O}

\section{Keywords}

quality of wood

dry rate

dryind curve

defects

final moisture

\section{Palavras-chaves} qualidade da madeira taxa de secagem curva de secagem defeitos umidade final

\begin{abstract}
A B S T R A C T
Air dryng of the lumber to eucalipto.

The difficulty of obtaining dry wood quality is one major obstacle when it comes to drying of Eucalyptus wood, since the species of this genus have slow drying and high propensity to defect. In this sense, the objective of this work was to evaluate the effect of drying in the air, on the quality of Eucalyptus spp, in order to identify the optimal time of permanence of the wood in the drying yard. In the drying process was accompanied by the humidity loss and the drying rate, the defects were measured before and after each drying (warping, cracks and collapse) and tension levels and humidity gradient after drying. The results showed that pre-air drying took 65 days to reach $23 \%$ of final humidity, with an average drying rate of $1 \%$ / day with low defect rates and drying tensions moisture gradients were medium were $20.22 \%$ to $23.18 \%$ outer layer and inner layer, and the average gradient $3.17 \%$.
\end{abstract}

\section{R E S U M O}

A dificuldade de se obter madeira seca com qualidade é um dos maiores obstáculos quando se trata da secagem da madeira do gênero Eucalyptus, visto que as espécies do gênero apresentam secagem lenta e com alta propensão a defeitos. Nesse sentido o trabalho teve como objetivo avaliar o efeito da secagem ao ar livre, na qualidade da madeira de Eucalyptus spp., visando identificar o tempo ótimo de permanência da madeira no pátio de secagem. No processo de secagem acompanhou-se a perda de umidade e a velocidade de secagem, foram mensurados os defeitos antes e após cada secagem (empenamentos, rachaduras e colapso) bem como os níveis de tensão e de gradiente de umidade após a secagem. Os resultados mostraram que a secagem ao ar livre levou 65 dias para atingir $23 \%$ de umidade final, apresentando uma taxa de secagem média de 1\%/dia, com baixos índices de defeitos e de tensões de secagem. Os gradientes de umidade foram de $20,22 \%$ para camada externa e 23,18\% camada interna, sendo o gradiente médio de $3,17 \%$. 


\section{INTRODUÇÃO}

A indústria ainda enfrenta dificuldades quanto à secagem da madeira de eucalipto, muitas vezes por falta de conhecimento técnico ou por erros operacionais, aliado a isso, à secagem do eucalipto apresenta características próprias que a tornam uma madeira de difícil secagem, o que muitas vezes a maioria das indústrias prefere adotar outras espécies como matéria prima principal.

A escolha de um determinado método de secagem influencia no tempo de secagem, na qualidade do material seco e também na obtenção do teor de umidade desejado para determinada finalidade. É possível reduzir o tempo de secagem e a incidência de defeitos, quando o processo é conduzido de modo adequado Susin et al. (2014). Nesse sentido, para a madeira apresentar baixo indicie de defeitos, diminuir custos com energia e apresentar maior qualidade final, a secagem ao ar livre torna-se uma alternativa para indústria que requer produtos com ótimo acabamento e estabilidade dimensional.

A secagem ao ar consiste no empilhamento da madeira serrada em pátios, deixando-a exposta aos fatores ambientais, permitindo secar naturalmente até que esta atinja a umidade de equilíbrio do ambiente (Zen, 2016). A taxa de secagem depende principalmente da temperatura, da umidade relativa do ar e da velocidade do vento. Apesar de não necessitar de alto investimento inicial, há o inconveniente de demandar mais tempo se comparada a outros métodos, além de apresentar um teor de umidade final que apresenta limitações para certos usos da madeira Susin et al. (2014).

Os fatores relacionados à madeira, pátio de secagem, arranjo das pilhas e as condições climáticas são os principais fatores a serem considerados na secagem ao ar livre. Conforme Ducatti et al. (2001) a pilha de madeira sendo construída de maneira inadequada irá contribuir fortemente para a ocorrência de defeitos na madeira. A velocidade do vento é a variável que apresenta maior relevância na secagem ao ar livre e a organização das pilhas no pátio de secagem irá influenciar na sua eficiência. Segundo Klitzke (2005) vários fatores podem influenciar na velocidade de secagem da madeira, dentre eles se destacam: a espécie, a espessura das tábuas, o teor de umidade inicial, o local, as variáveis ambientais, entre outros.

A secagem ao ar livre da madeira de eucaliptos, torna-se um método interessante que pode ser usado também de formas alternativas, como o método combinado (pré-secagem mais secagem artificial em estufa), onde a pré-secagem retira lentamente a água livre, diminuindo as tensões na madeira e posteriormente a remoção da água de im- pregnação é finalizada em estufa, evitando rachaduras e defeitos como o colapso. Stangerlin et al. (2009) e Braz et al. (2015) recomendam uma secagem em dois estágios para madeira, iniciando com uma secagem ao ar livre e em seguida uma secagem em câmara convencional, visando à manutenção da qualidade da madeira com a redução do tempo de secagem na câmara de secagem. Esta combinação de métodos proporcionará redução de custos e maior eficiência do processo, Braz et al. (2015) consideram que o teor de umidade ideal para secagem ao ar livre estaria entre 20 e $40 \%$.

Segundo Denig et al. (2000) a secagem ao ar tem como objetivo retirar a água livre reduzindo a umidade da madeira em torno de 25 a $30 \%$ para consequentemente reduzir o tempo de secagem em estufa, para que isso aconteça eficientemente é necessário obter um teor umidade homogêneo entre as tábuas.

O conhecimento prévio da variabilidade da madeira, aliada a uma secagem conduzida corretamente, pode resultar em benefícios para o controle de possíveis defeitos e melhorar a qualidade da madeira, aumentando seu aproveitamento no beneficiamento final, gerando produtos de alta qualidade $\mathrm{e}$ inserindo cada vez mais estudos com secagem ao ar livre com diferentes espécies de eucalipto.

Dessa forma, o presente trabalho teve como objetivo avaliar o efeito da secagem ao ar livre, na qualidade da madeira de Eucalyptus spp., identificando o tempo de permanência da madeira no pátio de secagem.

\section{MATERIAL E MÉTODOS}

\section{Preparo do material}

A madeira serrada de Eucalyptus spp., com idade média de 15 anos utilizada no estudo foi cedida pela empresa Mademape, localizada em Campina Grande do Sul (PR). As tábuas apresentaram dimensões nominais de $25 \mathrm{~mm}$ x $110 \mathrm{~mm}$ x $2.500 \mathrm{~mm}$ (espessura, largura e comprimento), na condição "verde", onde posteriormente foram separadas e transportadas para as dependências do Laboratório de Secagem da Madeira, na Universidade Federal do Paraná (UFPR), localizada em Curitiba (PR) para realização da secagem ao ar livre.

Para o monitoramento das variáveis ambientais durante a secagem ao ar livre, foi instalado próximo à pilha um psicrômetro analógico, além disso, foram coletados os dados das variáveis ambientais no Sistema Meteorológico do Paraná (SIMEPAR) localizado no Centro Politécnico da UFPR.

A pilha de secagem, foi montada sobre piquetes 
de concreto a uma altura $30 \mathrm{~cm}$ do solo, sendo construída na dimensão nominal de $1.200 \times 1.000 \mathrm{x}$ $2.500 \mathrm{~mm}$ (altura, largura e comprimento) com 25 camadas de tábuas. Para separação das tábuas foram utilizados sarrafos separadores previamente preparados com seção transversal de $24 \mathrm{~mm}$ x 24 $\mathrm{mm}$, com faces paralelas e distribuídos paralelamente a uma distância de $350 \mathrm{~mm}$ entre os sarrafos
(Figura 1). A disposição da pilha seguiu a orientação dos ventos predominantes NE, a velocidade média encontrada na pilha com anemômetro foi de $0,5 \mathrm{~m} . \mathrm{s}^{-1}$. Para cobertura da pilha foram utilizadas 4 telhas de fibra-cimento com $6 \mathrm{~mm}$ de espessura, com objetivo de diminuir a incidência dos raios solares e de precipitações nas tábuas.

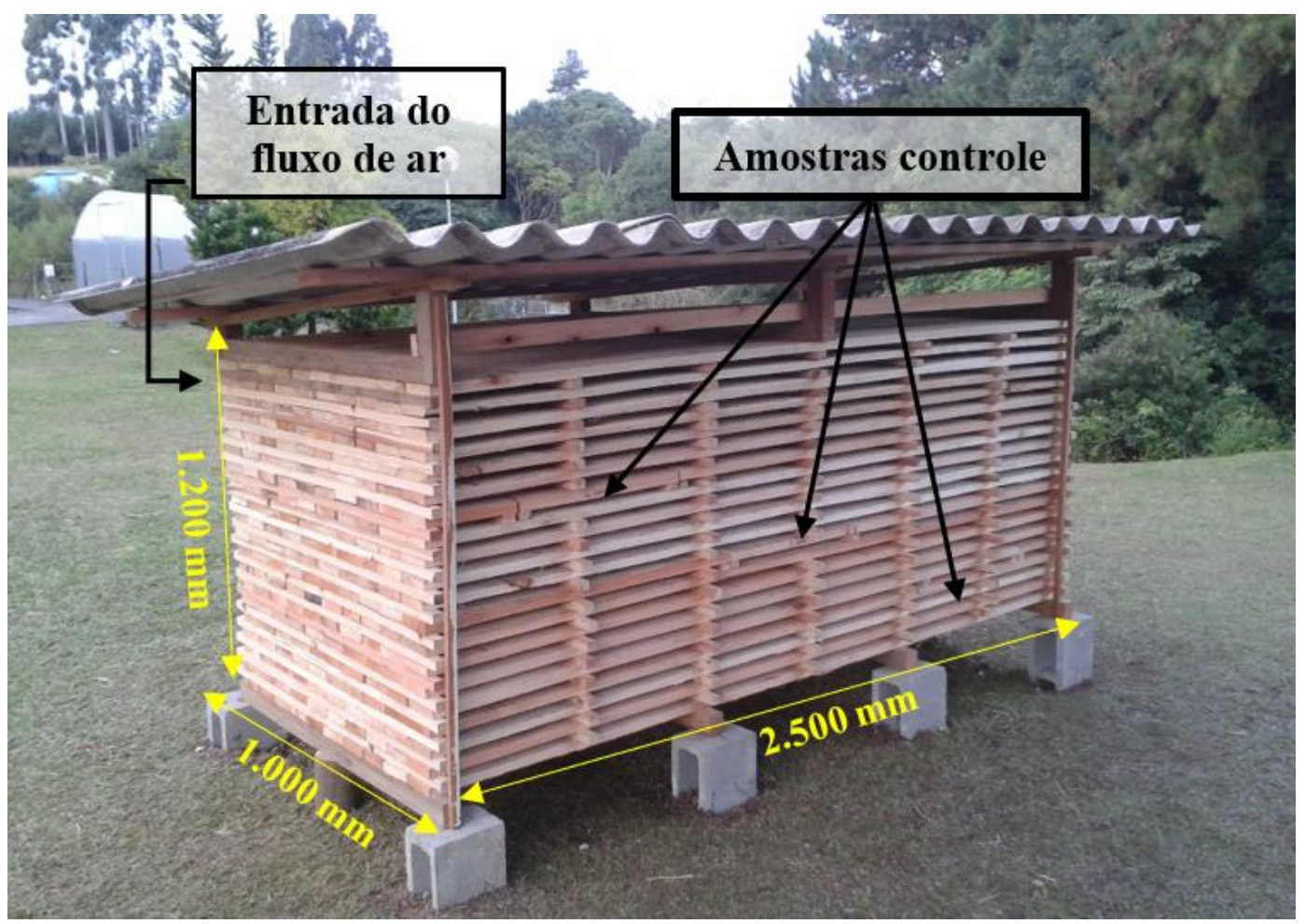

Figura 1 - Pilha de secagem ao ar livre da madeira de Eucalipto.

\section{Monitoramento da umidade, taxa de secagem, defeitos e qualidade final}

Para acompanhar o teor de umidade durante a secagem foram utilizadas seis amostras de controle com dimensões de $25 \mathrm{~mm}$ x $110 \mathrm{~mm}$ x $550 \mathrm{~mm}$ (espessura, largura e comprimento), tendo seus topos impermeabilizados, conforme Simpson (1991). Antes do início do processo de secagem, determinou-se o teor de umidade inicial de cada amostra de controle, mediante recomendação de Galvão \& Jankowsky (1985). Posteriormente as amostras foram distribuídas na pilha; sendo três localizadas na entrada do ar e três amostras na saída do ar, dispostas na base, meio e topo para melhor controle da umidade, conforme Figura 1.

O monitoramento do teor de umidade durante o processo de secagem através das amostras de controle foi realizado a cada dois dias até a obtenção do teor de umidade final desejado. A perda de umidade neste ensaio foi acompanhada com base na Equação 1, conforme Brandão (1989).

$$
U A=\frac{M A \cdot(U i+100)}{M i}-100
$$

Em que: UA: umidade atual (\%); MA: massa do corpo de prova nesse mesmo instante $(\mathrm{g})$; Ui: umidade inicial do corpo de prova (\%); Mi: massa inicial do corpo de prova (g).

Com base nos dados obtidos pela da perda de umidade ao longo do tempo foi determinada a taxa de secagem para madeira de eucalipto, para as três fases da secagem: de verde a $30 \%$, de $30 \%$ ao TU final e de verde até TU final (Equação 2).

$$
T S=\frac{T U i-T U f}{T}
$$

Em que: TS: taxa de secagem $\left(\mathrm{U} \% \cdot \mathrm{h}^{-1}\right)$; TUi: teor de umidade inicial (\%); TUf: teor de umidade final (\%); T: (tempo em dias).

Também para um melhor acompanhamento da umidade em toda pilha e para avaliar qualidade das 
tábuas quanto aos defeitos de secagem, foram selecionadas 50 tábuas, onde estimou-se a massa seca das tábuas em função da determinação umidade inicial pelo método gravimétrico e do peso inicial de cada tábua (Equação 3).

$$
M S E=\frac{100 \cdot M i}{100+U i}
$$

Em que: $\mathrm{MSE}=$ massa seca estimada $(\mathrm{g}) ; \mathrm{Mi}=$ massa inicial das tábuas $(\mathrm{g}) ; \mathrm{Ui}=$ umidade inicial das amostras (\%).

Posteriormente as 50 tábuas foram distribuídas na pilha de forma aleatória, os defeitos avaliados foram arqueamento, encurvamento, encanoamento e rachaduras de superfície e de topo seguindo as recomendações da NBR 14806 (ABNT, 2002). O Índice de Rachaduras de Topo (IRT) foi calculado através do somatório de todas as rachaduras de topo em cada face, pelo comprimento da tábua. Foram consideradas como tábuas defeituosas aquelas cujo defeito está acima do admitido para a quarta classe da norma, adotando-se a classificação pela pior face da tábua. A qualidade final da secagem quanto teor de umidade final, gradiente de umidade e as tensões de secagem foram analisadas após a secagem seguindo recomendação de Simpson (1991) com as mesmas 50 tábuas selecionadas.

\section{RESULTADOS E DISCUSSÃO}

O teor de umidade inicial médio foi de $94 \%$, com desvio padrão de $23,1 \%$ e coeficiente de variação de $24,5 \%$. Os valores variaram de 64 a $149 \%$ de umidade inicial (Figura 2). O processo de secagem foi finalizado quando a madeira atingiu $23 \%$ de teor de umidade final médio, com desvio padrão de $2,0 \%$ e coeficiente de variação de $8,7 \%$ num tempo de 65 dias. Os valores de umidade final variaram de 19 a $26 \%$ entre as tábuas.

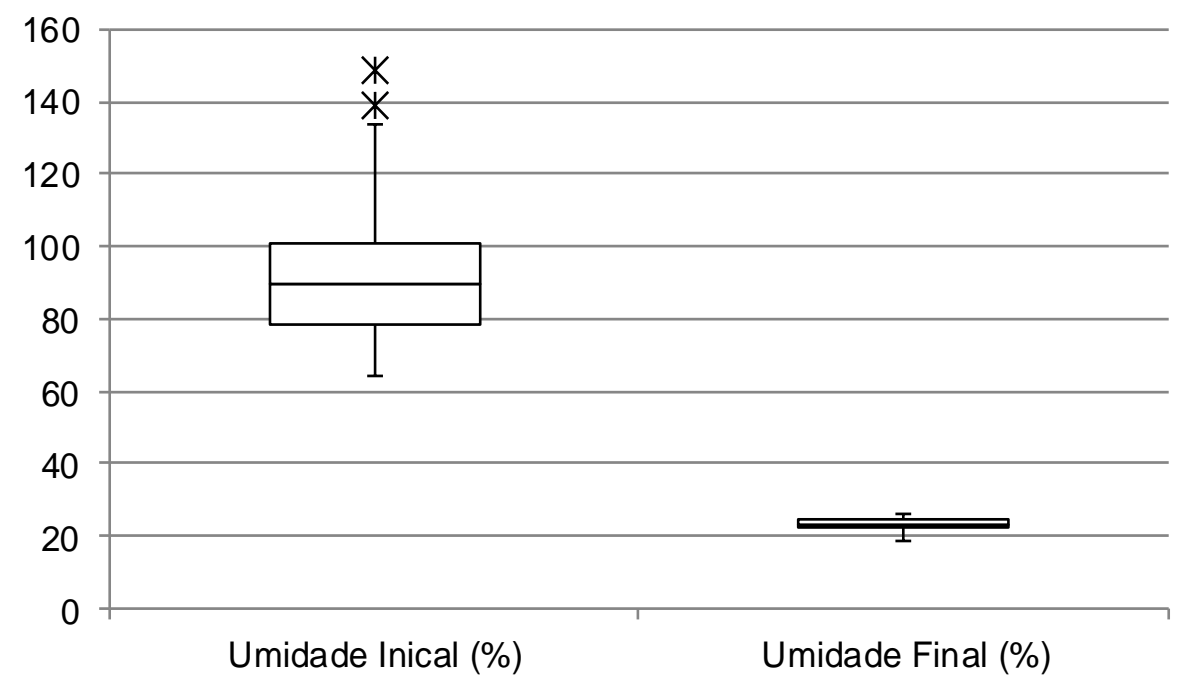

Figura 2 - Teor de umidade inicial e seus outliers e o teor de umidade final das tábuas após a secagem, com a dispersão dos dados.

Pode-se observar na figura 1 que o teor de umidade inicial e final para secagem apresentou baixa variação dos dados comprovando a eficiência do processo, assim como uma baixa variação entre as tábuas. Os resultados encontrados de teor de umidade inicial e final (Figura 2) para a madeira de eucalipto ao ar livre estão de acordo com os resultados obtidos por Duarte et al. (2015). Santos et al. (2003) recomendam que a secagem natural seja interrompida quando o teor de umidade da madeira estiver entre 20 e $40 \%$, a partir do qual seria mais eficiente a secagem convencional.

A madeira avaliada conforme a figura 2 apresentou variação de umidade nas tábuas entre 22 a 44\%, com desvio padrão de 10,1 e $33 \%$ de coeficiente de variação, por esse motivo deu-se sequência a secagem, sendo finalizada com 65 dias. Quando a madeira atingiu em média $22 \%$ de umidade, sendo encontrada baixa dispersão dos dados de umidade entre as tábuas (desvio padrão de 2,6\% e coeficiente de variação de $16,8 \%$ ) e homogeneidade entre as peças. Segundo Denig et al. (2000) para que a madeira decorrente de um processo de secagem ao ar livre seja eficiente para uma posterior secagem convencional é necessário que o teor de umidade seja homogêneo entre as tábuas.

$\mathrm{Na}$ figura 3 pode se observar o comportamento da curva de perda de umidade no tempo, associando a umidade de equilíbrio. 


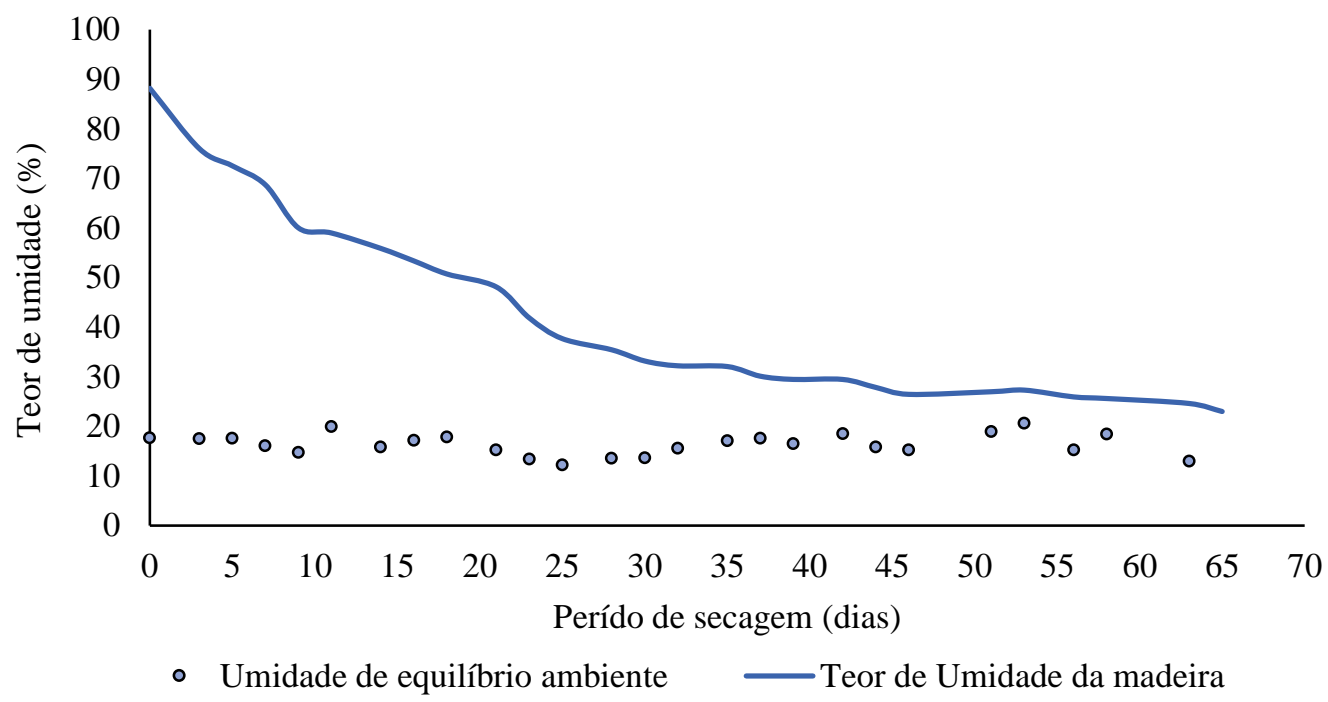

Figura 3 - Curva de secagem ao ar livre e umidade de equilíbrio do ambiente para secagem da madeira de eucalipto.

Conforme a figura 3 a pré-secagem ao ar livre da madeira de eucalipto foi finalizada com 65 dias. Os valores observados apresentaram a mesma tendência encontrada por Duarte et al. (2015), que durante a primavera obtiveram 63 dias de secagem ao ar livre para madeira de eucalipto, na cidade de Frederico Westphalen (RS), para que seu teor de umidade inicial de $54 \%$ atingisse $15,5 \%$.

Nota-se na figura 3 que a madeira apresentou a perda de umidade de forma constante, apesar de serem constatados períodos de chuva intermitentes durante a secagem. A partir do $35^{\circ}$ dia ocorreu uma redução drástica da velocidade de secagem com certa estabilização do teor de umidade, levando 30 dias para o TU cair de $32 \%$ de para $23 \%$. Esta dificuldade foi causada pela retirada em grande parte da água de impregnação da madeira (Kliztke, 2005). Porém esse período, entre 32 e $23 \%$ foi fundamental para que ocorresse uma maior homogeneidade da umidade entre as tábuas em toda pilha, ficando comprovado este resultado quando observado o baixo coeficiente de variação obtido no teor de umidade final das tábuas.

Pode-se destacar ainda (Figura 2) o curto período que as tábuas levaram para atingir o PSF (ponto de saturação das fibras, próximo aos $30 \%$ de teor de umidade), sendo esse de 39 dias, durante este período de secagem, ocorreram altas temperaturas, atí- picas dessa época (outono-inverno), que favoreceram a secagem reduzindo o teor de umidade da madeira de forma mais acelerada. Em nenhum momento houve um ganho de massa das amostras de controle, nem durante a remoção da água livre e nem na remoção da água de impregnação, demonstrando que a perda de umidade ocorreu normalmente, períodos chuvosos e mais úmidos não proporcionaram aumento no teor de umidade da madeira.

Nota-se na figura 3 que as tábuas ao final da secagem apresentaram um teor de umidade acima da umidade de equilíbrio do ambiente (UEa), a madeira ficou com 23,0\% numa UEa de $15,8 \%$. Esses resultados foram satisfatórios principalmente pelo fato do objetivo da secagem ao ar livre ser para realizar uma pré-secagem, ou seja, uma secagem intermediária, sendo necessário finalizar a secagem em estufa convencional até um teor de umidade final desejado.

\section{Taxa de secagem}

As taxas de secagem médias obtidas nas condições de teor de umidade de verde até $30 \%$ (retirada da água capilar), 30 até $22 \%$ (retirada da água de difusão) e de verde até $22 \%$ (retirada da água capilar e de difusão) são apresentadas na tabela 1.

Tabela 1 - Taxa de secagem ao ar livre para madeira de eucalipto função do tipo de remoção de água.

\begin{tabular}{lcc}
\multicolumn{1}{c}{ Faixas de umidade } & $\begin{array}{c}\text { T.S (U\%.dia } \\
\text { Média }\end{array}$ & CV\% \\
\hline Verde a 30\% & 1,50 & 21,5 \\
$30 \%$ a 22\%. & 0,25 & 32,3 \\
Verde a 22\% & 1,00 & 21,3 \\
\hline
\end{tabular}

T.S = Taxa de secagem $\left(U \% \cdot\right.$ dia $\left.^{-1}\right) ; \mathrm{CV} \%$ = Coeficiente de variação (\%) 
Pode se observar uma velocidade de secagem baixa em todas as faixas das taxas de secagem analisadas com forte variação dos resultados encontrados (Tabela 1). A velocidade de secagem na retirada da água capilar foi 6,0 vezes maior do que a retirada da água de impregnação. Duarte et al. (2015) encontraram valores de taxa de secagem superiores em média de 7,5 vezes maior na retirada da água capilar para Eucalyptus spp., enquanto que Santos et al. (2003), encontraram taxa de secagem inferior de 4,6 vezes maior na retirada da água capilar durante a secagem da madeira de Eucalyptus grandis. A retirada da água livre por capilaridade apresenta maior taxa de secagem quando comparada com a água de impregnação ligada na parede celular (Klitzke e Batista, 2010; Monteiro et al., 2018; Nascimento et al., 2019), a qual é retirada por difusão, e que as características da madeira e o aproveitamento das condições climáticas irão influenciar na taxa de secagem (Santos et al., 2003; Klitzke e Batista, 2010). Para espécies do gênero Eucalyptus esse movimento de difusão sofre restrições pelas características anatômicas da espécie (Monteiro et al., 2017), com predomínio de pontuações de pequenos diâmetros e com vasos usualmente bloqueados por tilose, tornando a madeira impermeável (Vermaas, 2000).

Quando comparamos a velocidade de secagem com outras espécies de folhosas, Susin et al. (2014) analisando amostras de Hovenia dulcis submetidas a secagem ao ar livre obtiveram uma velocidade de
8,9 vezes maior na retirada da água capilar. Monteiro et al. (2018) relataram velocidade de 8,2 vezes maior na retirada da água livre quando comparada a água adsorvida durante a secagem de toras de diferentes materiais genéticos de Eucalyptus. Ambos estudos com resultados bem superiores aos encontrados no presente estudo.

Neste estudo na faixa de 30 a $22 \%$, na remoção da água de impregnação (Tabela 1), a taxa de secagem reduziu $83,33 \%$, evidenciando que nessa faixa a remoção da água de impregnação é muito difícil e lenta, principalmente pelo fato da água da madeira estar aderida na parede celular. Jankowsky e Santos (2003) resumem a secagem da madeira em três etapas, sendo a terceira fase (fase da difusão) iniciada quando a linha de evaporação de água se restringe ao centro da tábua, não havendo mais água livre no material e a taxa de secagem será regulada pelas condições ambientais aplicadas e pelas características do material, até que o teor de umidade de equilíbrio seja alcançado.

\section{Defeitos de secagem - rachaduras de superfície e topo}

Seguindo os critérios da NBR 14806 (ABNT, 2002), a porcentagem de tábuas com rachaduras de superfície foi de $26 \%$ após secagem ao ar livre (Tabela 2) e o índice de rachaduras de topo de 4,7\%.

Tabela 2 - Rachaduras de superfície e de topo submetidas a secagem ao ar livre.

\begin{tabular}{lcc}
\multicolumn{1}{c}{ Avaliação } & $\begin{array}{c}\text { Rachadura de superfície mé- } \\
\text { dio }(\boldsymbol{\%})\end{array}$ & IRT médio (\%) \\
\hline Após desdobro & 6 & 2,5 \\
Após secagem & 26 & 4,7 \\
\hline
\end{tabular}

IRT médio= índice de rachaduras de topo.

Apesar do alto valor encontrado para a percentagem de rachaduras de superfície (Tabela 2) as tábuas apresentaram alta qualidade, sendo classificadas como de primeira e segunda qualidade. As rachaduras de superfície eram de pequena extensão e superficiais e não afetaram a qualidade da madeira. Stangerlin et al. (2009) encontrou valores um pouco inferiores a este estudo para E. saligna com 16,36\% das tábuas com rachaduras de superfície seca ao ar livre.

Com relação ao índice de rachaduras de topo (IRT) apresentados na tabela 2, verificou-se que após a secagem ocorreram baixos índices desse defeito. De acordo com a norma utilizada nenhuma tábua foi classificada com defeituosa (Tabela 2). Estes resultados estão de acordo com Stangerlin et al. (2009) que encontraram valores de IRT para a secagem ao ar de 4,1\%, 5,8\% antes e após a secagem para madeira de E. saligna. A possível explicação para o baixo índice de rachaduras de topo pode ser o baixo gradiente de umidade encontrado, aliado as condições de secagem suave e também pelo fato de a madeira ser coberta após o empilhamento, fazendo com que os raios solares não incidissem diretamente nas tábuas, diminuindo dessa forma as rachaduras. Mendes et al. (1998) ao testarem o comportamento de 25 espécies do gênero $E u$ calyptus na secagem ao ar livre, concluíram que em 
relação aos parâmetros de qualidade relacionados as rachaduras, é possível se obter madeira serrada deste gênero com qualidade satisfatória exigida pelo setor moveleiro, desde que se tenha um desenvolvimento e acompanhamento rígido das condições de secagem, bem como técnicas corretas de empilhamento.

\section{Defeitos de secagem - empenamentos}

Os resultados médios obtidos dos empenamentos, quanto ao arqueamento, encurvamento e encanoamento para madeira de Eucalyptus spp. encontram-se na Tabela 3. Verificou-se que após secagem da madeira ao ar livre as tábuas apresentaram menor índice de arqueamento, e que $36 \%$ das tábuas apresentaram esse defeito.

Tabela 3 - Empenamentos na secagem ao ar livre na madeira de Eucalyptus.

\begin{tabular}{lcccc}
\hline Tipo de Empenamento & Após desdobro & \% Defeito & Após secagem & \% Defeito \\
\hline Arqueamento $(\mathrm{mm} / \mathrm{m})$ & 1,36 & 80 & 0,58 & 36 \\
Encurvamento $(\mathrm{mm} / \mathrm{m})$ & 1,91 & 64 & 1,34 & 62 \\
Encanoamento $(\mathrm{mm})$ & 0 & 0 & 0,46 & 28 \\
\hline
\end{tabular}

A redução na flecha média do arqueamento conforme a Tabela 3, pode ser justificada pelo fato de que a madeira de eucalipto após o desdobro libera suas tensões, e que ao longo do processo de secagem ao ar, em condições não controláveis das variáveis ambientais, essas tensões vão sendo "aliviadas" e os índices de arqueamento vão diminuindo ao longo da secagem. O arqueamento é um defeito que pode estar associado às tensões de crescimento e que no momento do desdobro acaba ficando aparente, conforme Rocha e Tomaselli (2002) a manifestação deste defeito está mais associada às tensões de crescimento ainda presentes nas tábuas do que ao processo de secagem. $\mathrm{O}$ arqueamento é um defeito que se manifesta durante o desdobro e que pode ser intensificado durante a secagem.

Ainda na tabela 3 pode-se analisar que logo após o desdobro, as tábuas já apresentaram encurvamento e que após a secagem ocorreu uma redução na flecha média, onde após a secagem $62 \%$ das tábuas apresentaram esse defeito. A redução deste empenamento se deve provavelmente à ação do peso das próprias tábuas (restrição) e ao correto empilhamento e alinhamento dos sarrafos separadores, foram os fatores preponderantes na redução do índice. Batista et al. (2015) encontraram redução no encurvamento médio após a secagem de espécies de eucaliptos, Rocha e Tomaselli (2002) afirmam que o principal fator de redução do encurvamento é a restrição mecânica do empilhamento. Segundo Simpson (1991) e Denig et al. (2000) o encurvamento não é um defeito problemático da madeira, uma vez que pode ser eliminado facilmente durante o processo de empilhamento da carga de madeira.

Tanto para o arqueamento quanto para o encurvamento, nenhuma tábua apresentou flecha superior de $5 \mathrm{~mm}$ conforme o estabelecido pela norma, podendo afirmar que a madeira apresentou alta qualidade após a secagem e que as tábuas foram classificadas como adequadas para serem usadas na produção de produtos de maior valor agregado.

$\mathrm{O}$ encanoamento não foi observado na condição verde (após desdobro) (Tabela 3), pois este defeito está associado às diferenças de contração entre os planos tangencial e radial, quando seca. Porém após a secagem, o encanoamento esteve presente em $28 \%$ das tábuas, com um índice de $0,46 \mathrm{~mm} . \mathrm{m}^{-1}$. A presença de tábuas encanoadas ocorre principalmente em tábuas com orientação tangencial/radial, ou seja, em tábuas que estão próximas da medula e apresentam uma face tangencial e outra radial, ocorrendo devido os diferentes índices de contração entre as faces tangencial e radial. Susin et al. (2014) verificaram um aumento na flecha média de $1,17 \mathrm{~mm} \cdot \mathrm{m}^{-1}$ após o desdobro e $1,63 \mathrm{~mm} \cdot \mathrm{m}^{-1}$ após secagem de Hovenia dulcis seca ao ar livre.

\section{Gradiente de umidade e tensões de secagem}

As tábuas apresentaram gradiente de umidade médio após a secagem ao ar livre de 3,17\%. Em média as tábuas apresentaram um teor de umidade interno de $23,32 \%$ (cv\% de 7,04\%) e um teor de umidade externo de $20,15 \%$ (cv\% 4,74\%). Tal gradiente apesar de ser considerado elevado não ocasionou elevados índices de defeitos. $\mathrm{O}$ fato se deve provavelmente ao teor de umidade final (23\%) nas tábuas estar próximo ao ponto de saturação das fibras (PSF), o que justifica os baixos índices de defeitos encontrados. Batista et al. (2015) encontraram em média gradiente de umidade na secagem em estufa convencional valores inferiores ao deste estudo. 


\section{CONCLUSÕES}

Com os resultados obtidos com a secagem da madeira serrada de Eucalyptus é possível concluir que:

- O Teor de umidade final médio encontrado foi próximo à umidade de equilíbrio da região e com baixa variação dentro da pilha;

- O teor de umidade final homogêneo na pilha para uma pré-secagem ao ar foi alcançado com 65 dias de secagem;

- A taxa de secagem foi maior na remoção de água livre, apresentando-se de forma constante.

- A secagem ao ar livre apresentou baixos índices de defeitos, tornando alta a qualidade da madeira após a secagem ao ar livre.

\section{REFERÊNCIAS BIBLIOGRÁFICAS}

ASSOCIAÇÃO BRASILEIRA DE NORMAS TÉCNICAS (ABNT). NBR 1480: Madeira serrada de eucalipto - Requisitos. Rio de Janeiro: ABNT, 11p. 2002.

BATISTA, D.C.; KLITZKE, R.J.; ROCHA, M.P. Proposta de programa de secagem para a madeira de "guajará" $(M i-$ cropholis venulosa Mart. et Eichler). Ciência da Madeira, v.3, n.1, p.22-32, 2012.

BATISTA, D.C.; KLITZKE, R.J.; ROCHA, M.P. Qualidade da secagem convencional conjunta da madeira de clones de três espécies de Eucalyptus sp. Ciência Florestal, v.25, n.3, p.711-719, 2015.

BRANDÃO, A.T.O. Determinação de metodologia para a indicação de programas de secagem de madeiras.1989. 100 p. Dissertação (Mestrado em Ciências Florestais), Escola Superior de Agricultura "Luiz de Queiroz", Universidade de São Paulo, Piracicaba.

BRAZ, R.L.; DUARTE, A.P.C.; OLIVEIRA, J.T.S.; MOTTA, J.P.; ROSADO, A.M. Curva característica de secagem da madeira de Tectona grandis e Acacia mangium ao ar livre. Floresta e Ambiente, v.22, n.1, p.117-123, 2015.

DENIG, J.; WENGERT, E.M.; SIMPSON, W.T. Drying hardwood lumber. Gen. Tech. Rep. FPL-GTR-118. Madison, WI: U.S. Department of Agriculture, Forest Service, Forest Products Laboratory. 138p., 2000.

DUARTE, M.M.; TREVISAN, R.; SUSIN, F., ZEN, L.R.; VALERIUS, J. Drying curve and defects of Eucalyptus sp. wooden submitted to air drying. Spanish Journal of Rural Development, v.5, n.3, p.161-170, 2015.

DUCATTI, M.A.; JANKOWSKY, I.; ANDRADE, A. Condições operacionais da secagem convencional em indústrias madeireiras no município de Tietê, SP. Scientia Forestalis, n.59, p.101-113, 2001.

GALVÃO, A.P.M.; JANKOWSKY, I.P. Secagem racional da madeira. 1.ed. São Paulo, 111p. 1985.

JANKOWSKY, I.P.; SANTOS, G.R.V. Secagem da madeira serrada de eucalipto. Circular Técnica- IPEF. n.199, 2003.
KLITZKE, R.J. Manual de secagem de madeira. Apostila técnica. Curitiba, 119p. 2005.

KLITZKE, R.J.; BATISTA, D.C. Ensaio de taxa de secagem e escore de defeitos para a predição da qualidade de secagem convencional da madeira de Eucalyptus. Scientia Forestalis. v.38, n.85, p.97-105, 2010.

MENDES, A.S.; MARTINS, V.A.; MARQUES, M.H.B. Programas de secagem para madeiras brasileiras. Brasília. Instituto Brasileiro do Meio Ambiente e dos Recursos Naturais Renováveis, 114p. 1998.

MONTEIRO, T.; LIMA, J.; SILVA, J.; ZANUNCIO, A.J.; BARAÚNA, E. Water flow evaluation in Eucalyptus and Corymbia short logs. Floresta e Ambiente. v.25, n.2, e20170659. 2018. http://dx.doi.org/10.1590/21798087.065917

MONTEIRO, T.C.; LIMA, J.T.; HEIN, P.R.G.; SILVA, J.R.M.; TRUGILHO, P.F.; BOLOGNANI, H.B. Efeito dos elementos anatômicos da madeira na secagem das toras de Eucalyptus e Corymbia. Scientia Forestalis. v.45, n.115, p.493-505, 2017. https://doi:dx.doi.org/10.18671/scifor.v $45 \mathrm{n} 115.07$

NASCIMENTO, T.M.; MONTEIRO, T.C.; BARAÚNA, E.E.P.; MOULIN, J.C.; AZEVEDO, A.M. Drying influence on the development of cracks in Eucalyptus logs. Bioresources, v.14, n.1, p.220-233, 2019.

ROCHA, M.P.; TOMASELLI, I. Efeito do modelo de desdobro na qualidade da madeira serrada de Eucalyptus grandis e Eucalyptus dunnii. Cerne, v.8, n.2, p.070-083, 2002.

SANTOS, G.R.V.; JANKOWSKY, I.J.; ANDRADE, A. Curva característica de secagem para madeira de Eucalyptus grandis. Scientia Forestalis, n.63, p.214-220, 2003.

SIMPSON, W.T. Dry kiln operator's manual. Madison: U.S. Department of Agriculture, 274p. 1991.

STANGERLIN, D.M.; SANTINI, E.J., SUSIN, F.; MELO, R.R.; GATTO, D.A.; HASELEIN, C.R. Uso de estufa solar para secagem de madeira serrada. Ciência Florestal, v.19, n.4, p.461-472, 2009.

SUSIN, F.; SANTINI, E.J.; STANGERLIN, D.M.; MOARIS, W.W.C.; MELO, R.R. Taxa de secagem e qualidade da madeira serrada de Hovenia dulcis submetida a dois métodos de secagem. Floresta e Ambiente, v.21, n.2, p.243$250,2014$.

VERMAAS, H.F. A review of drying technology for young fast-grown eucalypts. IUFRO, the future of eucalypts for wood products, Tasmania, 2000. Proceedings. Tasmania: IUFRO, p.225-237. 2000.

ZEN, L.R. Métodos combinados para secagem da madeira de Eucalyptus: pré-secagem ao ar livre com secagem em estufa convencional. 2016. 106p. Dissertação (Mestrado em Engenharia Florestal). Universidade Federal do Paraná, Curitiba. 